\title{
Causes of visual impairment and blindness in children in three ecological regions of Nepal: Nepal Pediatric Ocular Diseases Study
}

This article was published in the following Dove Press journal:

Clinical Ophthalmology

25 August 2015

Number of times this article has been viewed

\section{Srijana Adhikari' \\ Mohan K Shrestha' \\ Kamala Adhikari \\ Nhukesh Maharjan' \\ Ujjowala D Shrestha'}

'Pediatric Ophthalmology unit, Tilganaga Institute of Ophthalmology, Gaushala, Kathmandu, Nepal;

${ }^{2}$ Private consultant, Kathmandu, Nepal
Purpose: To study the causes of blindness and visual impairment in children in three ecologically diverse regions of Nepal.

Materials and methods: This is a baseline survey report of a 3-year longitudinal population-based study. One district each from the three ecological regions - Terai, Hills, and Mountains - was selected for the study. Village Development Committees from each district were selected by random sampling. Three community health workers were given training on vision screening and identification of abnormal ocular conditions in children. Health workers who examined children and collected data using pretested questionnaire performed house-to-house surveys. Children with abnormal vision or ocular conditions were referred to and examined by pediatric ophthalmologists.

Results: A total of 10,950 children aged 0-10 years, 5,403 from Terai, 3,204 from Hills, and 2,343 from Mountains, were enrolled in the study. Of them, $681(6.2 \%)$ were nonresponders. The ratio of boys to girls was 1.03:1. Prevalence of blindness was $0.068 \%$ (95\% confidence interval $[\mathrm{CI}] 0.02 \%-0.12 \%)$ and visual impairment was $0.097 \%$ (95\% CI $0.04 \%-0.15 \%)$. Blindness was relatively more prevalent in Terai region $(0.08 \%, 95 \%$ CI $0.02 \%-0.13 \%)$. The most common cause of blindness was amblyopia (42.9\%) followed by congenital cataract. Corneal opacity (39\%) was the most common cause of unilateral blindness.

Conclusion: More than two-thirds of the causes that lead to blindness and visual impairment were potentially preventable. Further, nutritional and genetic studies are needed to determine the factors associated with ocular morbidity and blindness in these regions.

Keywords: vision screening, ocular morbidity, childhood, Nepal, pediatric

\section{Introduction}

Visual disorders represent one of the most common disabling and handicapping conditions in children. ${ }^{1}$ Childhood blindness is one of the priorities of Vision 2020: "The Right to Sight". ${ }^{2}$ It is estimated that approximately 1.4 million blind children worldwide, two-thirds of whom live in the developing countries. ${ }^{3}$ Causes of childhood blindness vary according to region and socioeconomic conditions. ${ }^{2,3}$ Population-based data vis-à-vis prevalence and causes of childhood ocular morbidity and blindness are limited worldwide, including Nepal., ${ }^{4,5}$ Nationwide survey-based data for childhood blindness collected from the schools for the blind has been reported in Nepal. ${ }^{6}$ Nepal, a land-locked country divided into three distinct geographical regions, comprises a large area of plains to the south (Terai), a hilly region in the central interior (Hills), and a high mountainous area to the north (Mountains). Each of these ecological regions has its own traditional values, climate, environment, religion, ethnicity, and
Crijana Adhikari

Tilganga Institute of ophthalmology, GPO Box 56I, Gaushala,

Kathmandu 44600, Nepal

Tel +977 | 4493684

Fax +977 | 4474937

Emailsrij_a@yahoo.com 
socioeconomic status. Accordingly, various factors that contribute and determine health problems. Many countries have adopted a variety of screening tools for vision screening in preschool- and school-aged children. ${ }^{7-9}$ We had previously trained community health workers in vision screening techniques for children. These personnel work in primary health centers and are directly involved in the community health care. The Nepal Pediatric Ocular Diseases Study was a 3-year population-based longitudinal study. In this study, we report data on baseline surveys. In the first part, we analyzed various risk factors associated with childhood ocular morbidity. ${ }^{10}$ This paper focuses on the causes of visual impairment and blindness in these children.

\section{Materials and methods}

The study was approved by institutional review board of Tilganga Institute of Ophthalmology, Kathmandu, Nepal, and adheres to the tenets of the Declaration of Helsinki.

\section{Study area}

Nepal has three distinct geographical regions: a large area of plains to the south (Terai), a hilly region in the central interior (Hills), and a high mountainous area to the north (Mountains). Each region comprises many districts within each of which there are Village Development Committees (VDCs). Sarlahi (Terai region), Makwanpur (Hills region), and Sindhupalchowk (Mountain region) districts were selected for the study. Thus, each of the three regions was represented in the study. Four Village Development Committee from the Terai, two from the Hills, and three from the Mountain regions were selected according to sample size.

\section{Study population}

All the children from 0 to 10 years of age residing in the selected geographical areas were included in the study.

\section{Sample size and sampling method}

The sample size calculation was done by using the formula of estimation of population proportion with specified relative precision. Taking the prevalence of $5 \%$, the relative precision of $10 \%$, and considering the design effect of 1.5 , a total sample size of 10,950 was needed for this study. Sample size was proportionately taken from the three selected districts according to the population projection of 2011. Based on these calculations, 2,343 children taken from the Sindhupalchowk, 3,204 from the Makwanpur, and 5,403 from the Sarlahi regions were recruited for this study. One district from each ecological region were selected by purposive sampling and the VDCs were selected by simple random sampling.

\section{The field examination}

Three local community health workers were recruited for three districts. They were trained for recording visual acuity (VA) using HOTV matching chart in preverbal children and tumbling $\mathrm{E}$ chart in older children. They were also given training on detecting abnormal ocular conditions in children by using torch light. As a part of their training, health workers were shown photographs and children with these abnormal signs in the outpatient clinic. The abnormal signs included red eye, white pupillary reflex, watering, deviation, and head tilt. Special data collection form was designed. The form was pretested in a similar community in the Kathmandu valley. Informed consent was obtained from all the parents of children included in the study.

The health workers carried out a house-to-house survey. The field examination included the following steps:

1. Assessment of vision was accomplished according to age. In children who were $<4$ years of age, visual assessment was accomplished using the torch light fixation preference method. Children who were 4-6 years of age were examined using the HOTV matching test at a distance of $3 \mathrm{~m}$. In children $\geq 6$ years, vision was assessed using the tumbling E chart.

2. Height and weight were recorded.

3. Torch light examination was done to find out abnormal ocular signs.

4. Motility examination was performed.

5. Cover test was also performed.

\section{Examination of abnormal children}

Children with vision of $<6 / 9$ in either eye or who had any abnormal ocular conditions were referred to an examination site (close to their home), where they were examined by a pediatric ophthalmologist or pediatric-oriented ophthalmologist from Tilganga Institute of Ophthalmology. VA examinations were performed according to the child's age, as mentioned earlier. Anterior segment examination was performed using a handheld slit lamp (Kowa, Japan) and posterior segment examination by direct ophthalmoscopy (Heine, Munich, Germany). Retinoscopy was performed using a streak retinoscope (Heine). Blindness was taken as the presenting VA of $<6 / 60$ in the better eye. Visual impairment was taken as the presenting VA of $<6 / 18-6 / 60$ in the better eye.

\section{Statistical analysis}

Data entry was accomplished using version 3.1 Epi data (Epidata, Denmark). Data analysis was accomplished using SPSS software, version 16.5 (SPSS Inc., Chicago, IL, USA). Age-adjusted prevalence of ocular morbidity, visual 
Table I Age and sex distribution of children in the three ecological regions

\begin{tabular}{|c|c|c|c|c|}
\hline & Terai & Hills & Mountains & Total \\
\hline & Number (\%) & Number (\%) & Number (\%) & Number (\%) \\
\hline \multicolumn{5}{|c|}{ Age group (years) } \\
\hline $0-5$ & $2,036(39.1)$ & $\mathrm{I}, 264(40.3)$ & $585(30.4)$ & $3,885(37.8)$ \\
\hline$>5-10$ & $3,172(60.9)$ & I,872 (59.7) & $|, 34|(69.6)$ & $6,385(62.2)$ \\
\hline \multicolumn{5}{|l|}{ Sex } \\
\hline Female & $2,516(48.3)$ & I,583 (50.5) & $989(5 \mathrm{I} .3)$ & $5,088(49.5)$ \\
\hline Male & $2,692(51.7)$ & I,553 (49.5) & $937(48.7)$ & $5,182(50.5)$ \\
\hline
\end{tabular}

impairment, and blindness with a 95\% confidence interval (CI) was calculated for each defined geographical area. A $P$-value of $<0.05$ was considered significant.

\section{Results}

A total of 10,950 children were enrolled in the study. Six hundred eighty $(6.2 \%)$ children were excluded from the data analysis, either as a result of absence or because their parents were unwilling to give consent at the time of examination. A total of 5,208 (50.7\%) children from the Sarlahi district, $3,136(30.5 \%)$ from the Makwanpur district, and 1,926 (18.8\%) from the Sindhupalchowk district were included in the data analysis. The mean age of children was 5.7 years (standard deviation [SD] 3.1; range: $0-10$ years). The ratio of boys to girls was $1.03: 1$. In total, there were $50.5 \%$ boys and $49.5 \%$ girls. Age and sex distributions of children in the three geographical regions are shown in Table 1.

A total of $376(3.7 \%)$ children had some type of ocular morbidity. When considering presenting VA of $<6 / 60$ for blindness and $<6 / 18-6 / 60$ for visual impairment, we found that $0.068 \%$ of children were blind and $0.097 \%$ of children were visually impaired. Hence, prevalence of blindness and visual impairment in the community was $0.068 \%(95 \%$ CI $0.02 \%-0.12 \%)$ and $0.097 \%$ (95\% CI $0.04 \%-0.15 \%)$, respectively. Table 2 illustrates age-adjusted prevalence of visual impairment and blindness in the three ecological regions.

Blindness was relatively more prevalent in the Terai region ( $P=0.08 ; 95 \% \mathrm{CI} 0.02 \%-0.13 \%)$. No cases of visual impairment were detected from the Mountain region in our study.
According to this study, visual impairment and blindness in most of the cases were caused by amblyopia, the most common cause of which was uncorrected refractive error, contributing $80 \%$ to visual impairment and $42.9 \%$ to blindness. Similarly, congenital cataract and strabismus (having congenital fibrosis syndrome and amblyopia) contributed $10 \%$ to visual impairment. Cataract, microphthalmus, and retinal disease were also observed in blind children (Table 3 ). Table 4 shows the distribution of diseases causing blindness and visual impairment according to the region.

While analyzing the causes of unilateral blindness in these children, we found that corneal opacity was the most common cause accounting for $39 \%$ of the cases (Table 5 ).

\section{Discussion}

Data on childhood blindness are generally obtained either from surveys assessing blindness in all age groups or from those assessing a particular disease of interest, eg, vitamin A deficiency or refractive error. ${ }^{11}$ Very few epidemiological studies have focused primarily on childhood blindness.

There are no population-based epidemiological data for Nepal on the precise prevalence of blindness in children. Shrestha et al conducted a nationwide survey in schools for the blind in Nepal. ${ }^{6}$ A similar study was done by Kansakar et al in Western Nepal. ${ }^{12}$. These studies, however, were not population-based and gave information only on etiology but not prevalence. The Nepal Blindness Survey of 1981 showed childhood blindness to be $<0.01 \%$ in children aged $<4$ years and $0.08 \%$ in children aged $5-10$ years. ${ }^{13}$ We found no study that compared childhood ocular morbidity patterns in the three geographically diverse regions of Nepal. Thus, ours is the

Table 2 Crude and age-adjusted prevalence of blindness ${ }^{\mathrm{a}}$ and visual impairment ${ }^{\mathrm{b}}$

\begin{tabular}{llllll}
\hline Region & \multicolumn{2}{l}{ Blindness, \% $\mathbf{9 5 \%}$ Cl) } & & & Visual impairment, \% (95\% Cl) \\
\cline { 2 - 3 } & Crude & Age-adjusted & & Crude & Age-adjusted \\
\hline Terai & $0.07(0.02-0.13)$ & $0.08(0.02-0.13)$ & & $0.09(0.04-0.15)$ & $0.08(0.02-0.13)$ \\
Hills & $0.06(0.01-0.11)$ & $0.07(0.02-0.11)$ & & $0.16(0.06-0.24)$ & $0.17(0.07-0.24)$ \\
Mountains & $0.05(0.02-0.11)$ & $0.06(0.01-0.11)$ & 0 & 0 \\
\hline
\end{tabular}

Notes: aPresenting VA of $<6 / 60$ in the better eye. 'Presenting VA of $<6 / 18$ in the better eye.

Abbreviations: $\mathrm{Cl}$, confidence interval; $\mathrm{VA}$, visual acuity. 
Table 3 The causes of visual impairment ${ }^{\mathrm{a}}$ and blindness ${ }^{\mathrm{b}}$

\begin{tabular}{lll}
\hline Diseases & $\begin{array}{l}\text { Visual impairment, } \\
\text { N (\%) }\end{array}$ & $\begin{array}{l}\text { Blindness, } \\
\text { N (\%) }\end{array}$ \\
\hline Amblyopia & $8(80)$ & $3(42.9)$ \\
Congenital cataract/aphakia & $\mathrm{I}(10)$ & $2(28.6)$ \\
Microphthalmus & 0 & $\mathrm{I}(14.3)$ \\
Retinal diseases & 0 & $\mathrm{I}(14.3)$ \\
Strabismus (congenital fibrosis) & $\mathrm{I}(10)$ & 0 \\
Total & $10(100)$ & $7(100)$ \\
\hline
\end{tabular}

Notes: apresenting VA of $<6 / 18$ in the better eye. 'Presenting VA of $<6 / 60$ in the better eye.

Abbreviation: VA, visual acuity.

only study that provides the epidemiological data on Nepalese children. Nepal has an estimated population of 29 million, including 11.3 million children $<16$ years of age. ${ }^{14}$ It has been estimated that 30,240 Nepalese children are blind and another 90,000-120,000 children visually impaired. ${ }^{15}$ The sources for these data comprise information from the local eye hospitals, schools for the blind, and published and unpublished data from Nepal. The Rapid Assessment of Avoidable Blindness study estimated the infant mortality rate-based prevalence of childhood blindness to be $0.05 \%{ }^{16}$

Of the affected children in our study, approximately $80 \%$ had avoidable causes of blindness and visual impairment. Children in the Terai region were more prone to blindness compared to the other two regions. Congenital abnormalities accounted for the primary causes of blindness in the Terai region. The Nepal Blindness Survey of 1981 showed congenital cataract and nutritional diseases to be the major causes of childhood blindness. However, our study shows amblyopia and refractive error to be the major causes of blindness in Nepalese children, and shows a changing pattern of blinding diseases over time. The findings of our study are similar to the population-based study carried out in South India (Kariapatti Eye Evaluation Project). ${ }^{8}$ Moreover, there is a decreasing trend in nutritional diseases, perhaps due to the effectiveness of nutritional intervention programs in Nepal.

In our study, we trained community health care workers in vision screening techniques. Furthermore, in our previous study,

Table 4 Pattern of ocular diseases causing blindness and visual impairment according to the geographic distribution

\begin{tabular}{|c|c|c|c|c|c|c|c|c|}
\hline \multirow[t]{2}{*}{ Pattern of diseases } & \multicolumn{2}{|c|}{ Total } & \multicolumn{2}{|c|}{ Terai } & \multicolumn{2}{|c|}{ Hills } & \multicolumn{2}{|c|}{ Mountains } \\
\hline & $\overline{\mathbf{N}}$ & $\%$ & $\overline{\mathbf{N}}$ & $\%$ & $\overline{\mathbf{N}}$ & $\%$ & $\mathbf{N}$ & $\%$ \\
\hline Ambly & 35 & 9.4 & 13 & 11.2 & 13 & 16.7 & 9 & 5.0 \\
\hline Congenital catara & 6 & 1.6 & 3 & 2.6 & 2 & 2.6 & I & 0.6 \\
\hline Microphthalmus & 3 & 0.8 & 3 & 2.6 & 0 & 0.0 & 0 & 0.0 \\
\hline Retinal diseases & 3 & 0.8 & 3 & 2.6 & 0 & 0.0 & 0 & 0.0 \\
\hline Strabismus (congenital fibrosis) & 50 & 13.4 & 12 & 10.3 & 16 & 16.7 & 22 & 12.2 \\
\hline
\end{tabular}

Table 5 Causes of unilateral blindness

\begin{tabular}{ll}
\hline & Unilateral blindness, N (\%) \\
\hline Corneal opacity & $7(39)$ \\
Coloboma & $2(1 \mathrm{I})$ \\
Congenital cataract & $2(1 \mathrm{I})$ \\
Microphthalmus & $2(1 \mathrm{I})$ \\
Optic atrophy & $2(1 \mathrm{I})$ \\
Phthisis bulbi & $\mathrm{I}(5.5)$ \\
Anophthalmus & $2(1 \mathrm{I})$ \\
Total & $18(100)$ \\
\hline
\end{tabular}

we reported on the positive validity (sensitivity, $89 \%$ ) of using community health care workers for vision screening in children. ${ }^{17}$

This is the first population-based study in Nepal addressing the prevalence of visual impairment and blindness in children. However, limitations in interpreting the findings of the study include the fact that, since this is a baseline survey, results mainly highlight the prevalence. We have tried to include three districts representing the three ecological regions. It would have been better if we could have included all the 75 districts of Nepal. However, it was not feasible in our context.

\section{Conclusion}

We found that approximately two-thirds of the cases of visual impairment and blindness were due to potentially preventable causes. Blindness and visual impairment were more prevalent in the Terai region. In this region, we found large numbers of children with congenital eye diseases. Further genetic and nutritional studies are needed to uncover the factors associated with ocular morbidity and blindness in the three ecological regions of Nepal. We recommend that future eye health programs in Nepal should focus more comprehensively on preventive actions, eg, correction of refractive errors and surgical removal of cataracts. Since ocular morbidity differs in each ecological region, programs should consider evidence-based management.

\section{Acknowledgment}

We would like to acknowledge The Fred Hollows Foundation, Australia, for providing the research grant to conduct the study.

\section{Disclosure}

The authors report no conflicts of interest in this work.

\section{References}

1. Gerali P, Flom MC, Raab EL. Report of Children's Vision Screening Task Force. Schaumburg, IL: National Society to Prevent Blindness; 1990 
2. World Health Organization. Global initiative for the elimination of avoidable blindness. Programme for the Prevention of Blindness and Deafness. Geneva: WHO; 1997. Contract no: (WHO/PBL/97.61).

3. World Health Organization. Preventing blindness in children: report of WHO/IAPB scientific meeting. Programme for the Prevention of Blindness and Deafness, and International Agency for Prevention of Blindness. Geneva: WHO; 2000. Contract no: (WHO/PBL/00.77).

4. Steinkuller PG, Du L, Gilbert C, Foster A, Collins ML, Coats DK. Childhood blindness. J AAPOS. 1999;3(1):26-32.

5. Dandona L, Gilbert CE, Rahi JS, Rao GN. Planning to reduce childhood blindness in India. Ind J Ophthalmol. 1998;46(2):117-122.

6. Shrestha JB, Gnyawali S, Upadhyay MP. Causes of blindness and visual impairment among students in integrated schools for the blind in Nepal. Ophthal Epidemiol. 2012;19(6):401-406.

7. Muhit MA, Shah SP, Gilbert CE, Hartley SD, Foster A. The key informant method: a novel means of ascertaining blind children in Bangladesh. Br J Ophthal. 2007;91(8):995-999.

8. Nirmalan PK, Vijayalakshmi P, Sheeladevi S, Kothari MB, Sundaresan K, Rahmathullah L. The Kariapatti pediatric eye evaluation project: baseline ophthalmic data of children aged 15 years or younger in Southern India. Am J Ophthalmol. 2003;136(4):703-709.

9. Dorairaj SK, Bandrakalli P, Shetty CR V, Misquith D, Ritch R. Childhood blindness in a rural population of southern India: prevalence and etiology. Ophthal Epidemiol. 2008;15(3):176-182.

10. Adhikari S, Shrestha MK, Adhikari K et al. Factors associatd with childhood ocular morbidity and blindness in three ecological regions of Nepal: Nepal Pediatric ocular Diseases Study. BMC Ophthalmol. 2014;14:125. Available from: http://www.biomedcentral.com/14712415/14/125. Accessed October 2014
11. Gilbert CE, Anderton L, Dandona L, Foster A. Prevalence of visual impairment in children: a review of available data. Ophthal Epidemiol. 1999;6(1):73-82.

12. Kansakar I, Thapa HB, Salma KC, Ganguly S, Kandel RP, Rajasekaran S. Causes of vision impairment and assessment of need for low vision services for students of blind schools in Nepal. Kathmandu Univ Med J. 2009;7(25):44-49.

13. Brilliant LB, Pokhrel RP, Grasset NC et al. Epidemiology of blindness in Nepal. Bull World Health Org. 1985;63(2):375-386.

14. Central Bureau of Statistics. In: Nepal National Population and Housing Census 2011; editor. Kathmandu, Nepal: Central Bureau of Statistics Nepal; 2011:23.

15. Apex Body for Eye Health Ministry of Health and Population Nepal. Mid Term Review of Vision 2020: The Right to Sight. Kathmandu, Nepal: Apex Body for Eye Health Ministry of Health and Population Nepal; 2011.

16. Nepal Netra Jyoti Sangh. The Epidemiology of Blindness in Nepal. Kathmandu, Nepal: Nepal Netra Jyoti Sangh; 2012

17. Adhikari S, Shrestha U. Validation of performance of certified medical assistants in preschool vision screening examination. Nep JOphthalmol. 2011;3(6):128-135.
Clinical Ophthalmology

\section{Publish your work in this journal}

Clinical Ophthalmology is an international, peer-reviewed journa covering all subspecialties within ophthalmology. Key topics include: Optometry; Visual science; Pharmacology and drug therapy in eye diseases; Basic Sciences; Primary and Secondary eye care; Patient Safety and Quality of Care Improvements. This journal is indexed on

Submit your manuscript here: http://www.dovepress.com/clinical-ophthalmology-journal

\section{Dovepress}

PubMed Central and CAS, and is the official journal of The Society of Clinical Ophthalmology (SCO). The manuscript management system is completely online and includes a very quick and fair peer-review system, which is all easy to use. Visit http://www.dovepress.com/ testimonials.php to read real quotes from published authors. 